\title{
Development of a journal club on the Nursing management process
}

\author{
Desenvolvimento de um clube de leitura sobre o processo gerencial em enfermagem \\ Desarrollo de un club de lectura sobre el proceso de gestión en enfermeira
}

\section{Viviana Carolina Oyan de Moraes' \\ ORCID: 0000-0002-7874-0426 \\ Wilza Carla Spiri \\ ORCID: 0000-0003-0838-6633}

'Universidade Estadual Paulista Júlio de Mesquita Filho. Botucatu, São Paulo, Brazil.

How to cite this article: Moraes VCO, SpiriWC. Development of a journal club on the Nursing management process. Rev Bras Enferm [Internet]. 2019;72(Suppl 1):221-7. [Thematic Issue: Work and Management in Nursing]. DOI: http://dx.doi.org/10.1590/0034-7167-2018-0019

Corresponding Author: Viviana Carolina Oyan de Moraes E-mail: vivianabtu@hotmail.com

Submission: 02-15-2018

Approval: 05-25-2018

\section{ABSTRACT}

Objective: To develop a journal club on management topics in Nursing. Method: Action research, adopting content analysis as methodological reference and the journal club strategy. 12 nursing managers of a public hospital in the state of São Paulo participated from August to November 2016. Results: data showed the participation of nurses in the journal club in five meetings planned collectively with the following topics: "aspects regarding organization", with the subtopics "planning", "work process", "structure" and "people management"; and the topic "aspects regarding the team", with the subtopics "autonomy", "behavior/attitude", "awareness" and "social problems". Conclusion: The study showed the comprehensiveness of topics the journal club can address regarding management, and how scientific basis is important in the daily life of nursing managers to improve quality of care and the ability to manage.

Descriptors: Evidence-Based Nursing; Nursing Research; Practice Management; Education, Nursing, Continuing; Qualitative Research.

\section{RESUMO}

Objetivo: Desenvolver um clube de leitura sobre temas de gerenciamento em enfermagem. Método: Pesquisa-ação, adotando-se a análise de conteúdo como referencial metodológico e a estratégia do clube de leitura. Participaram 12 gerentes de enfermagem de um hospital público do estado de São Paulo no período de agosto a novembro de 2016. Resultados: os dados revelaram a participação dos enfermeiros no clube de leitura em cinco encontros planejados coletivamente e cujos temas foram: "aspectos referentes à organização", com os subtemas "planejamento", "processo de trabalho", "estrutura" e "gestão de pessoas"; e o tema "aspectos referentes à equipe", com os subtemas "autonomia", "comportamento/ atitude", "sensibilização" $\mathrm{e}$ "problemas sociais". Conclusão: O estudo mostrou a abrangência de temas que o clube de leitura pode abordar em relação ao gerenciamento e o quanto o embasamento científico é importante no cotidiano dos gerentes de enfermagem para melhorar a qualidade da assistência e a capacidade para gerenciar.

Descritores: Enfermagem Baseada em Evidências; Pesquisa em Enfermagem; Gerenciamento da Prática Profissional; Educação Continuada em Enfermagem; Pesquisa Qualitativa.

\section{RESUMEN}

Objetivo: Desarrollar un club de lectura sobre temas de gestión en enfermería. Método: Investigación-acción, adoptando el análisis de contenido como referencial metodológico y como la estrategia del club de lectura. Participaron 12 gerentes de enfermería de un hospital público del estado de São Paulo en el período de agosto a noviembre del 2016. Resultados: los datos revelaron la participación de los enfermeros en el club de lectura en cinco encuentros planeados colectivamente y cuyos temas fueron: "aspectos referentes a la organización", con los subtemas "planificación", "proceso de trabajo", "estructura" y "gestión de personas"; y el tema "aspectos referentes al equipo", con los subtemas "autonomía", "comportamiento/actitud", "sensibilización" y "problemas sociales". Conclusión: El estudio mostró el alcance de los temas que el club de lectura puede abordar en relación a la gestión, y la importancia del fundamento científico en el cotidiano de los gerentes de enfermería para mejorar la calidad de la asistencia y la capacidad para administrar.

Descriptores: Enfermería Basada en la Evidencia; Investigación en Enfermería; Gestión de la Práctica Profesional; Educación Continua en Enfermería; Investigación Cualitativa. 


\section{INTRODUCTION}

Nursing has been characterized as a work that involves processes in the perspective of care, management, education and research. Regarding the development of these work processes, there is a rationale that favors its fragmentation, especially concerning care and management, hindering the articulation of management with care.

Evidence-Based Management (EBM) can be described as the systematic application of the best evidence available to assess management strategies for developing and improving health services. Similarly, Evidence-Based Practices (EBP), in addition to the use of research results, it is also important to consider personal experience, expert opinions and patients' expectations ${ }^{(1)}$.

Nursing managers recognize the importance of using multiples sources of evidences - such as: researches performed in the area, institutional profile, institutions with similar profiles and the experience of the active group - to compose elements essential to the decision-making process. The role of the leader is indispensable to support and promote both EBP and EBM. However, functional management models (vertical and bureaucratic), the organizational culture, which does not favor this practice, and non-participation of workers can create barriers and hamper the work and efforts of the leader to the management process ${ }^{(2)}$.

A strategy used to increase the EBP is a journal club, which was introduced by the physician William Osler, in 1975, in McGill University, Canada, and in the John Hopkins Hospital, in 1980, in Europe, in order to improve interdisciplinary communication, education and to develop skills to read scientific articles ${ }^{(3)}$.

The purpose of Osler's journal club was to purchase and distribute periodicals to those who had no resources. However, over the following centuries, journal clubs took a variety of forms that evolved to meet the needs of the participants. Three objectives, however, have persisted over the years: to follow current literature, impact clinical practice and teach critical reading skills ${ }^{(4)}$.

This format of study has been used in Nursing as a way to improve skills and critical thinking, to discuss ideas and the knowledge of the research process. A place where periodic meetings are held, decided by the group to discuss research regarding clinical practice and to disclose research results, emphasizing the need for evidence-based practices ${ }^{(5)}$.

Participation in this study format helps nurses to develop interest in research, generating evidence-based activities and, consequently, improving several aspects of care and management ${ }^{(5)}$, however, the quality of a journal club, as well as its effectiveness, depends on the participating members in the process and in the results obtained, reading the article, expressing their perspectives, what they think about the subject and about the results and how it should be changed in the practice ${ }^{(6)}$.

There are several articles that can be explored in this type of meeting. In addition to the variety of topics, different types of scientific methods can also be explored and can generate rich and diverse dialogues among the participants and conduct a consensus for a better specific practice ${ }^{(6)}$.
This type of project helps to develop practice and interpretation of scientific articles, in addition to encourage professionals, through discussions, to develop the use of research evidences in decision-making ${ }^{(7)}$.

The national survey is still considered limited regarding the use of the journal club strategy. This allows the exchange of experiences, creating a collective learning, which improves the practice and management in nurses' daily lives.

\section{OBJECTIVE}

To develop a journal club on management topics in Nursing.

\section{METHOD}

\section{Ethical aspects}

The project was forwarded and approved by the Research Ethics Committee of the School of Medicine of Botucatu - São Paulo State University "Júlio de Mesquita Filho". Requirements determined by Resolution no. 466 of the National Health Council were followed. The participants were provided with information on the research and signed the Informed Consent Form (ICF). To ensure confidentiality and anonymity, the participants' name was replaced by the number of the audio recording.

\section{Theoretical-methodological framework}

Action research was used to develop topics regarding the managerial process, as this method allows researchers and participants to interact, enabling the transformation of the practice along with the active participation in the educational action ${ }^{(8)}$.

It is important to recognize that action research has several types of investigation. It is a generic term to any process that follows a cycle in which practice is enhanced by systematic oscillation between operating in the field of practice and investigating it. A change is planned, implemented, described and assessed to improve its practice, learning more in the course of the process, both regarding practice and the research itself(9).

\section{Study scenario}

The research was performed in a public hospital in São Paulo. It is a tertiary level general hospital, in partnership with the Brazilian Unified Health System (SUS - Sistema Único de Saúde), considered a teaching hospital by the Ministry of Education.

\section{Data source}

The inclusion criteria of the research participants were: to be in a managerial position, using as pattern to such definition the organizational chart established in the hospital unit, which consisted of 47 nursing managers. They were all invited to participate in the study.

The invitation for the journal club was written, explaining to the participants the objective of the study and strategy - which used social learning activities to integrate new knowledge to a context of experiences already lived. A total of 12 nursing managers participated of the research and signed the ICF. 


\section{Data collection and organization}

The meetings happened from August to November 2016, in person. Before the meetings, the participants were reminded of it by e-mail and phone messages.

For the journal club, as a learning environment, the following articulations were used:

a) explanation of the project relevance to the nursing board research scenario;

b) booking of an adequate place for carrying out the meetings;

c) providing equipment to record the meetings content;

d) inviting nursing managers participating in the research;

e) collaboration with a professor from the University, head office of the Nursing Graduate Program, to develop the topics to be agreed upon between the participants and the researcher.

The researcher and participants decided the periodicity of the meetings, the duration in hours and the organization of topics to reach the purposes. Five meetings were held, according to group suggestion. In the meetings, the number of participants varied (from eight to twelve nurses), inferring that, even with anticipated schedule and according to the participants' availability, the hospital demands, and the responsibility of these professionals prevented their presence in all meetings.

The journal club was conducted by the researcher, with her advisor as moderator. Their role was to stimulate discussions, so that ideas and integration of participants would occur during the meetings.

The meetings were recorded with the permission of all participants. The recording process was performed with microphones installed in the room, and each dialogue was transcribed using the number of the microphone identified.

Regarding the topics of the journal club, the researcher was responsible to find articles and previously e-mail them to the participants. The articles selected were recent and interesting for group discussion. The level of evidence of the articles varied from IV to $\mathrm{VI}^{(10)}$.

The participants committed themselves to read before the scheduled meetings, as suggested by them. In addition to the articles, upon the suggestion of the group itself, the researchers elaborated case studies based in literature so that they could be analyzed before the meetings and could contribute to the apprehension of the topic addressed in the journal club, allowing the articulation of theory with practice.

\section{Data analysis}

Data were analyzed considering the diagram proposed for action researches: planning, development, description and evaluation of the educational process. The discussions in the journal club, after recorded, were transcribed and independently encoded by the two main authors. The NVivo software was used to encode the transcriptions and assist in data organization.

Content analysis was adopted according to the Graneheim and Lundman referential to analyze the transcriptions. These authors state that content analysis in Nursing and Education research has been applied to a variety data of different levels of interpretation, and also clarify that the analysis of a text involves multiple meanings and some degree of interpretation ${ }^{(11)}$.

Data discussion was carried out in light of the Nursing management topic.

\section{RESULTS}

The 12 participants were female and from several sectors of the hospital: Intensive care unit (ICU), wards and special units, among others.

The topics and subtopics that emerged in the journal club are shown in Figure 1 below:

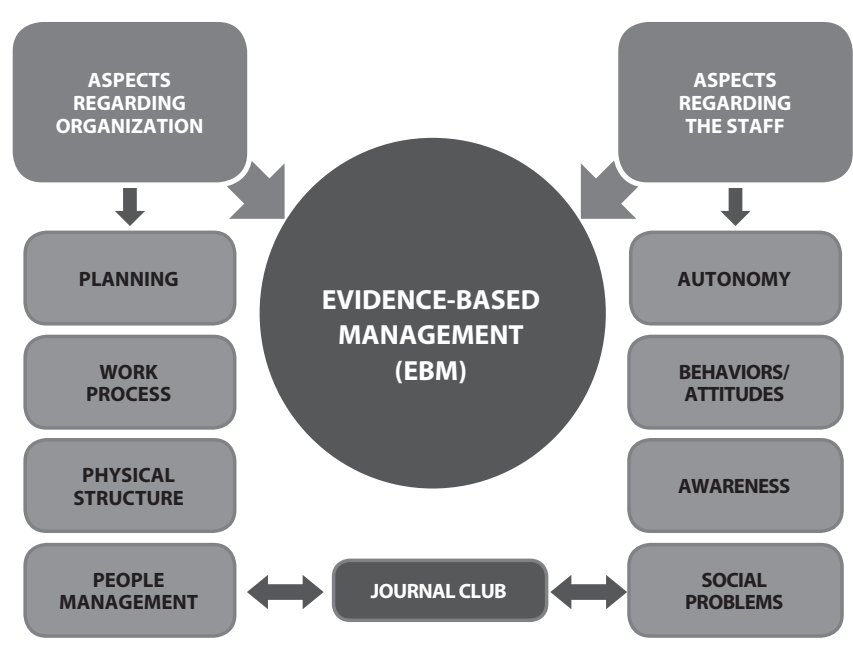

Figure 1 - Graphic representation of topics and subtopics that emerged in the journal club

In the topic "aspects regarding organization", the subtopics "planning", "work process", physical structure" and "people management" were unveiled.

The subtopic "planning" contemplates contradictory aspects, because, although it is recognized as indispensable to the work of a nurse, there are difficulties to carry it out, such as lack of time, priority and lack of planning knowledge as a care and management tool. The conversations indicate:

The planning here, it's a bit about the lack of time to plan, sometimes it happens a lot, because, as it's said here in the text, many times we put out the fire before planning, but, sometimes, because we really don't have the time... it's so immediate... and you need to solve it now, so you don't have time to plan how you'll make this decision, so, sometimes, in practice, things need to be faster than in theory. (Audio 6)

I think that planning is everything, both to give care and to manage... without planning, we can't work. (Audio 4)

The subtopic "work process" included the following meaning units: the establishment of routines and the organization of daily work of the nursing staff, especially the issue of noise in the work environment. In this sense, we approached, through the journal club, a motivator case, such as working with silence in inpatient units, which were mentioned as harmful both for professionals and patients, establishing it as a goal to be achieved. 
Isaw some services where a person used a coat with a different color, yellow, and they had a sign that was the color of a traffic light, and they... They didn't even need to talk, they'd just raise the sign and it worked, it was very interesting, and the environment was quite silent. (Audio 12).

So, we've the intention, it's to say this to the staff to raise awareness, make procedures in a lower tone, check the alarms and turn them off as soon as possible. Other actions, alert posters. (Audio 3).

The subtopic "physical structure" included significant units which emphasize the adequacy of physical structure to decrease noise and to better admit patients and workers, as well as the flow of people in the organization.

You reminded me of that patient... we had... structurally, the unit, and we've had a situation of patients saying that the noise, the crying bothers the others and affects people's vital signs. We had a patient in pain, right [name of a nurse], precordial because, the window opens onto the Pediatrics corridor, there was a death in Pediatrics, the family was desperately crying, and the mother was crying right under the patient's window. (Audio 3)

Yes, we don't have a physical structure to receive visits, they have to stay in the hall. (Audio 7)

"People management" had the subtopic "aspects regarding organization" and has the following significant units: management of nursing staff, creating work schedules and administrating of workers' absences, as the conversations quoted below reveal:

I think that, at least, the end-of-year schedule is a little, I won't say easy to make, but it's a little more negotiable, because it has two holidays, Christmas and New Year. (Audio 4)

In the ICU there is also Easter, some want [a day off on] Carnaval and some prefer Easter, then we can divide these two like that. (Audio 8)

The topic "aspects regarding the staff" contemplates the subtopics: "autonomy", "behavior/attitudes", "awareness" and "social problems".

The subtopic autonomy refers to the ability to lead and the freedom given to supervisors in face of conflicts and decisions in everyday work.

I think autonomy is what the nurses in the hospital, they have autonomy... to solve the situations in the sectors and mediate conflicts and negotiate, which I think is the most, it's a little more problematic, but that we end up following the steps from here. So, every time you have to mediate a conflict, to negotiate, we always meet before the party involved arrives, to plan what we'll say in that situation, how we'll solve it, we always have a plan $A$ and $B$, so, if the person behaves in a way, we follow a certain line, if they behave in another way, we follow another line so we aren't caught by surprise. (Audio 5)

I think we all have autonomy, we're there, no wonder there are supervisors, they're there to solve, make decisions through conflict mediation and negotiation (Audio 4).
In the subtopic "behavior/attitudes", the unit of meanings "individualism", "personality", "changes", "resistance" and "commitment" were observed in the following dialogues:

But then you have to seek help. We had in my area, including a nurse, we had complaints that she was rude, she screamed at people, at patients, at everything... So, we talked to her, and she said "look, I have this problem, I don't know if it's because of my hearing, but I can change", she looked for a speech therapist and started her therapy, and she got better, not 100\%, but she got a lot better, we had no other complaints. She wasn't rude, she spoke out loud, you could think she was arguing. (Audio 3)

I think the conflict is internal or external, so the difference of ideas, values, the culture, it interferes because people are beings that thinks for themselves, they have their ethical values or not, people are not the same... this doesn't mean that everybody has to think alike, because I think the richness of relationships, even professional relationships, comes from differences, but it can go beyond the respect that we've planned by the assistance or in interpersonal relationships. (Audio 8)

"Awareness" emerged as a subtopic mainly regarding noise, defining that constant orientation and involvement of the institution is needed to achieve this objective, expressed by the following dialogues:

The awareness of professionals in the problems caused by excessive noise, we'd need to have in our unit a noise sensor, I don't know how it's called, the equipment has a specific name, that would show us how loud it is, I read it in literature... it says to the professionals, sensitizing in the changes that the excessive noise does to the vital signs of the patients, it can cause tachycardia because of the fright, imagine, or if it's a baby, if it's too noisy the baby even has signs of... right? (Audio 2)

It's a way to raise awareness, which should be both in the unit, but I think it needs to be in the institution as a whole, a preventive and educational awareness program... Because when we are aware of what we can cause or receive, I think we behave in a different way... (Audio 3)

The subtopic "social problems" includes aspects concerning alcoholism and overload that are found in the work staff and affects their practice:

I already found a drunk employee on duty... She came to the exam drunk, a pre-employment examination, they passed her. (Audio 1)

It is so bad today, because we have less people to work with, so it seems that the problem is greater. (Audio 8)

At the end of the meetings, the participants performed a reaction assessment on the journal club, through an instrument that had four prognosticators with symbols of "great" $(-$, "good", "regular" and "bad" After the evaluations, the analyses were performed by the researchers, and everyone rated it as "great" and "good". There was also a space in the instrument for written observations, being them:

[...] of extreme importance for improving knowledge with professional development in decision-making. 
Reading generates knowledge on the subject.

I believe that, by reading articles, we can add knowledge and also see ourselves in the many realities presented

through this reading, we can add other experiences to the current way of management.

I think it's very important, updating theories and care practices. Certainly, reading scientific articles "helps" us to improve.

[...] it is very important, and I found the journal club interesting, since it brings the opportunity to discuss issues together, exchanging experiences. This exchange brings a big growth for the participants.

Scientific articles help both managerial and care decision-making, promoting evidence-based interpretations. It makes the daily work easier and can assist in planning activities and behaviors.

\section{DISCUSSION}

The journal club brought discussions regarding the organization aspects and the aspects regarding the staff. Regarding organization aspects, there is the planning issue, which was brought as an important process in daily life, however, the lack of knowledge on this process brings difficulties to implement it in practice.

Being considered an essential process discussed by several authors, planning is a continuous process in which knowledge of the environment and of the stages of the process to be planned is necessary, being an activity developed privately by the nurse due to the social and technical work division, in order to put an action in practice ${ }^{(12)}$.

In their work environment, nursing managers are faced with several realities and challenges, without, however, having a defined managerial model. Human, financial and physical resources are a few of the components that generate problems to be faced, and the immediate resolution does not always generate efficient work, being necessary to look beyond immediacy, thus, knowledge on management becomes a potential transformative instrument of practice ${ }^{(13)}$.

Some audios show clearly what literature brings regarding "putting out fire" in nurses' work, since they feel unproductive when planning their day and, thus, fail to work in a specific task. Daily planning is essential, because, without it, nurses find it difficult to start their work managing crises $^{(14)}$.

The topic "work process" discussed about the routines of the unit and the aspects regarding noise in the wards. Nursing managers need to reflect on the aspects relevant to their work environment, trying to rationalize time in order to do a few specific activities ${ }^{(14)}$. Concerning noise, it was a topic discussed as a priority, because, according to the nursing managers, it brings harm to professionals and patients and, through idea exchange, many strategies were elaborated to change the daily life in the environment in question.

Literature shows that: "exposure to excessive noise may cause hearing impairment, in addition to sleep disorders and mental rest $^{\prime \prime(15)}$, it can also generate stress, dissatisfaction with work, confusion and burnout ${ }^{(16)}$.

In front of the discussion on noises and patients' admission, the physical structure was a component discussed to improve hospital environment. Nursing management involves the analysis of the physical structure and environment for the best reception of patients and also of the team, ensuring their safety. The presence of the nurse in planning constructions of physical areas, internal and external, involving the hospital environment, is fundamental to ensure that planning takes place properly for the development of care activities, in addition to comfort and suitable work conditions ${ }^{(17)}$.

Concerning the involvement of nurses, the activities of these professionals were also mentioned in relation to people management regarding schedules, absenteeism and agreements involving workers were mentioned. The nurse group discussed the difficulty to perform work schedules in order to please all those involved, especially in holidays in which agreements are necessary between workers and the nursing managers, since staffing is not always adequate in the institution.

Absences in the institutions of the interviewed nurses, according to the words of those involved, have become common, mainly because it is a public institution. The reasons for absences are numerous, varying from an accident at work, psychological disorders, family issues, among others. Because the staff is in a complex work area, the lack of one worker overloads the rest, requiring greater speed in performing tasks, interfering in quality of care to the patient, and a cascade of illness in workers may occur. The nursing manager needs to create strategies of preventive actions for these workers' absence, improving and requiring better work conditions, including better staffing ${ }^{(18)}$.

As for the aspects regarding the staff, the question of autonomy was discussed by the nursing managers as something inherent to the role of the nurse, with freedom to solve daily problems and the decision-making process. Seen as an essential instrument in nursing, autonomy is defined by literature as "self-government capacity". This author still states that autonomy has been a subject in the construction process in nursing, since, in many situations, it is absent or non-existent, and that only through searching for specific knowledge, achieved through scientific evidences and improvement, the conquest of professional space and increase of autonomy will be possible for these professionals ${ }^{(19)}$.

Nursing management also involves human relations, a topic discussed in the conversations that express the difficulties of social relations, individualism, lack of commitment, among others. Some authors state that human groups are essential for the survival of social organizations, and the studies point out that patient care, considering its humanization, is influenced by the behavior of the staff. These conflicts have several reasons to exist, including those mentioned in the dialogues, in addition to the use of different ways to reach the same goals, the differences in values, overlapping or lack of clarity of goals, lack of information and personal problems ${ }^{(20)}$.

As discussed in literature, the awareness process requires a planned change to occur, and it is not an easy process, requiring the leaders to use their specific knowledges and skills, policies and relations so that the changes are not sabotaged ${ }^{(21)}$.

Some social problems faced by the participants in their daily life were also revealed, such as consumption of alcohol and work overload, which is evident in the individuals' conversation, impacting on quality of care. The great demand in hospitals, with 
exhausting works and unhealthy and stressful environments, in addition to daily contact with death and patients in serious conditions, leads to pressure, which can lead to alcohol consumption. A research involving alcohol consumption and illegal substances may help to understand the reason for their consumption by health professionals ${ }^{(22)}$.

This study caused nursing managers to reflect on the need and importance of exchanging experiences and, especially, of EBM, which can be put into practice, contributing, thus, for better management in the units where they work. It also contributed to updating the subjects discussed in relation to literature. As for the advances in participants' knowledge, it can be observed that there was an interest in knowing the experiences lived by colleagues and reading the articles in advance showed that the journal club contributed positively for the work of these managers.

The journal club is a strategy that promotes critical thought and research, since it allows to assess the validity and applicability of literature, improving professional skills ${ }^{(23)}$.

A study performed in Denmark demonstrated that this strategy can be useful and significant for nursing leaders, making them more confident of their skills to support a culture of practice and of EBM. Especially, it is a strategy that enables the dialogue between the participants and the recognition of areas that need to be addressed with positive results for the leaders and their team ${ }^{(23)}$.

\section{Study limitations}

There are few studies in Brazil that use the journal club strategy, especially in nursing management. The participants' presence varied in the meetings, but, because this is not a long-term study, it was not possible to observe changes in their lived reality. However, we believe that the possibility of articulating theory and practice is essential.

\section{Contributions to the nursing field}

This study caused the nursing managers to reflect on the need and the importance of basing their decision-making process in evidences, both through knowledge produced and disclosed and in the exchange of experiences between managers, allowing thus the EBM. The journal club strategy improves skills and critical thinking, allows the discussion of ideas and knowledge of the research process.

\section{CONCLUSION}

Studies involving journal clubs are still scarce in Brazil, and this study shows how effective this method can be for EBP, in this case with the effective participation of nursing managers in the hospital.

Through discussions and previously reading the articles, the participants could update their knowledge of literature regarding nursing management, in addition to exchange ideas and experiences about their professional daily lives.

The topics that involved aspects regarding organization brought items such as planning, work process, physical structure and people management. These subjects show how comprehensive are the activities developed by nursing managers in their daily life and how their participation in activities, including in hospital physical structure, is related to well-being of the nursing staff and of patients and their families. In addition, it was evident that their skills as staff coordinators can include problems such as absenteeism, leading them to perform interventions regarding people management, encouraging the workers to perform their activities focused on the patient and considering these workers' need as singular subjects.

Therefore, constant updating on nursing management is necessary to improve competencies, skills and attitudes and the development of an evidence-based managerial practice.

In the topic "aspects regarding the staff", which contemplates autonomy, behavior/ attitudes, awareness and social problems, we found out that there are different personalities in the work environment, as well as resistance to changes and egocentrism, which hinders the work of the nursing manager. The staff's behavior, according to the already discussed literature, directly affects the quality of patient care.

Still on this topic, it is highlighted that social problems involve facing situations such as drunk workers and other dependence problems, a cycle in which the overload can lead the worker to the use of these substances, causing devaluation, illness, absenteeism and also staff overload.

In summary, nursing management is a complex subject, requiring training from the professional who performs this activity in order to develop skills, abilities and attitudes. Scientific basis helps to ensure that this practice is consistent and applied, because, in the midst of the difficulties that are part of the daily life of management work, nursing managers can develop solutions and planning, consequently improving their own and the staff's quality of life, which affects the nursing care with their patients.

\section{REFERENCES}

1. Duffy JR, Thompson D, Hobbs T, Niemeyer-Hackett NL, Elpers S. Evidence-based nursing leadership evaluation of a joint academicservice journal club. J Nurs Adm [Internet]. 2011 [cited 2017 Dec 21];41(10):422-27. Available from: https://www.ncbi.nlm.nih.gov/ pubmed/21934429

2. Spiri WC, MacPhee M. The meaning of evidence-based management to Brazilian senior nurse leaders. J Nurs Scholarsh. 2013;45(3):265-72.

3. Resources JC. Temas e estratégias para liderança em enfermagem: enfrentando os desafios hospitalares atuais. Porto Alegre: Artmed; $2008.182 \mathrm{p}$.

4. Milbrandt EB, Vicent JL. Evidence-based medicine journal club. Crit Care [Internet]. 2004 [cited 2017 Dec 21];8(6):401-2. Available from: https://www.ncbi.nlm.nih.gov/pmc/articles/PMC1065082/

5. Jeanne STP. Changing nursing practice through a nursing journal club. Medsurg Nurs. 2005;14(6):390-2. 
6. Baker JD. Journal club as a resource for practice. AORN Journal [Internet]. 2013 [cited 2017 Dec 21];98(2):102-6. Available from: https://doi. org/10.1016/j.aorn.2013.06.001

7. Mattila LR, Rekola L, Koponen L, Eriksson E. Journal club intervention in promoting evidence-based nursing: perceptions of nursing students. Nurse Educ Pract. 2013;13(5):423-8.

8. Thiollentt M. Metodologia da pesquisa-ação. 15th ed. São Paulo: Cortez; 2007. 133 p.

9. Tripp D. Action research: a methodological introduction. Educ Pesqui [Internet]. 2005 [cited 2018 Feb 08];31(3):443-66. Available from: http://dx.doi.org/10.1590/S1517-97022005000300009

10. Stillwell SB, Fineout-Overholt E, Melnyk BM, Williamson KM. Evidence-based practice step by step: searching for evidence. Am J Nurs. 2010;110(5):41-7.

11. Graneheim UH, Lundman B. Qualitative content analysis in nursing research: concepts, procedures and measures to achieve trustworthiness. Nurse Educ Today. 2004;24(2):105-12.

12. Peres AM, Ciampone MHT. [Management and general nursing competencies]. Texto Contexto-Enferm [Internet]. 2006 [cited 2018 Apr 24];15(3):492-9. Available from: http://dx.doi.org/10.1590/S0104-07072006000300015. Portuguese.

13. Camelo SHH, Soares MI, Chaves LDP, Rocha FLR, Silva VLS. Nurse managers at a teaching hospital: training, responsibilities and challenges. Rev Enferm UERJ [Internet]. 2016 [cited 2017 Dec 21];24(3):1-6. Available from: http://dx.doi.org/10.12957/reuerj.2016.11637

14. Almeida ML, Segui MLH, Maftum MA, Labronici LM, Peres AM. [Management tools used by nurses in decision-making within the hospital context]. Texto Contexto-Enferm [Internet]. 2011 [cited 2017 Dec 21];20(spe):131-7. Available from: http://dx.doi.org/10.1590/S010407072011000500017. Portuguese.

15. Gregório DS. Riscos ocupacionais: uma revisão da literatura. Id On Line Rev Psicol [Internet]. 2017 [cited 2017 Dec 21];11(34):401-13. Available from: https://idonline.emnuvens.com.br/id/article/view/697

16. ChristofelHK et al. Análise do nível de ruído em unidade de terapia intensiva adulto. Rev Rene [Internet]. 2016 [cited 2017 Dec 21];17(4):55360. Available from: https://doi.org/10.14295/idonline.v11i34.697

17. Kurcgant et al. Gerenciamento em enfermagem. 3th ed. Rio de Janeiro: Guanabara; 2016. 199 p.

18. Martinato MCNB, Severo DF, Marchand EAA, Siqueira HCH. [Absenteeism in nursing: an integrative review]. Rev Gaúcha Enferm (Online) [Internet]. 2010 [cited 2017 Dec 21];31(1):160-6. Available from: http://dx.doi.org/10.1590/S1983-14472010000100022. Portuguese.

19. Gomes AMT, Oliveira DC. [Study of the structure of the professional autonomy in nursing's social representation]. Rev Esc Enferm USP [Internet]. 2005 [cited 2017 Dec 21];39(2):145-53. Available from: http://dx.doi.org/10.1590/S0080-62342005000200004. Portuguese.

20. Maestri V, Covalski D, Carbonara T, Gasperin T. Relações humanas no trabalho de enfermagem. Anuário Pesquisa e Extensão. 2016 ; 1:e12725.

21. Marquis BL, Huston CJ. Administração e liderança em enfermagem: teoria e pratica. 8 ed. Porto alegre: Artmed; 2015.653 p.

22. Barroso ML, Oliveira GF, Carvalho ACF, Batista HMT, Silveira GBM. The relationship between occupational stressors and coping strategies in nursing technicians. Texto Contexto-Enferm [Internet]. 2016 [cited 2018 Feb 08];25(4):e2920014. Available from: http://dx.doi. org/10.1590/0104-07072016002920014. English, Portuguese.

23. Cultivating a culture of research in nursing through a journal club for leaders: A pilot study. J Nurs Manag [Internet]. 2017 [cited 2017 Dec 21];26(1):42-9. Available from: http://dx.doi.org/10.1111/jonm.12518. 